AC 2009-2538: STRENGTHENING THE PERFORMANCE OF ENGINEERING AND TECHNOLOGY EDUCATORS ACROSS THE DISCIPLINES (SPEED)

J. P. Mohsen, University of Louisville 


\section{Strengthening the Performance of Engineering and Technology Educators Across the Disciplines (SPEED)}

\author{
James L. Melsa \\ Iowa State University \\ Naperville, IL
}

Dirk Schaefer

Georgia Institute of Technology

Savannah, GA

\author{
Tristan T. Utschig \\ Georgia Institute of Technology \\ Atlanta, GA
}

\author{
J.P. Mohsen \\ University of Louisville \\ Louisville, KY
}

Donald P. Visco, Jr.

Tennessee Technological University

Cookeville, TN

\section{Preamble}

For the past century, many organizations have published their visions of what the technological needs will be in the future for the United States and how the engineering profession might change to meet those needs. The Engineer of 2020 , released by the National Academy of Engineering in 2004, is a good example of the new vision.

Engineering and technology departments regularly adapt to the changing landscape so that their graduates will possess relevant skills and knowledge vital to potential employers. From an educational perspective, this will involve the development of new pedagogical approaches, the design of tailored programs and courses, novel ways to deliver them, etc. Examples of this include collaborative learning, cross-disciplinary courses, globally distributed project teams, and new forms of distance learning.

While a long history illustrates a changing engineering and technology curriculum to meet evolving technological needs, there has also been a long-standing call to strengthen engineering and technology educators' capabilities and preparation to perform the task of educating students. This latter call, however, has remained virtually unanswered for more than a century despite many calls, even from ASEE itself. It is time for US engineering and technology programs to act on this need and to extend faculty expertise with formalized professional development in education. Many countries around the world have already successfully introduced professional development programs for engineering faculty teaching in higher education. We should delay no further.

\section{Vision}

Our vision is simple: Implement a professional development program to Strengthen the Performance of Engineering and Technology Educators Across the Disciplines (SPEED). This program will help new tenuretrack engineering and technology faculty be better prepared to take on their educational mission. In its simplest form, new tenure-track faculty would successfully complete a program that will supplement and strengthen their capability to use essential skills and knowledge in the education-related aspects of their position.

\section{Implementation}

The SPEED program would typically last one or more years and would occur early-on during a faculty member's tenure track appointment. Individual institutions would retain flexibility in implementing the program. They would not necessarily need to have the same program structure and might utilize national workshops, educational classes, on-line offerings, mentor circles, etc.

\section{Content}

While the SPEED program would not necessarily be one standardized program, any SPEED program would contain three common critical elements: (1) approval of a nationally recognized society, such as ASEE, (2) inclusion of educational theory, practice, and scholarly activities with clear criteria and milestones, (3) flexibility in implementation across a variety of university administrative structures and cultures.

\section{Certification}

The SPEED program provides an opportunity for engineering and technology educators to become certified as an Educational Engineering and Technology Scholar once they complete a SPEED program. Also, they have the option to achieve the more advanced Educational Engineering and Technology Practitioner level and, ultimately, a master level leading to the designation Professional Engineering and Technology Educator. An organization such as ASEE would oversee the certification, though perhaps with the aid of selected engineering education programs and/or centers for teaching and learning (such as Virginia Tech, Purdue, Penn State, Georgia Tech, etc.). 


\section{Links to Accreditation}

In order to provide the proper motivation and buy-in for faculty participants, two elements are necessary. First, deans of engineering programs will need to recognize and promote the benefits of such a program along with supporting a program at their institution. Second, ABET (via Criterion 6: Faculty) would need to certify that a program is actually implementing their stated SPEED program. Since ASEE will have already certified program content, ABET would only need to confirm (during their accreditation visits) that the certified program is occurring. Such an approach would validate the "appropriate qualifications" of faculty, as prescribed within Criterion 6.

\section{Benefits for Faculty and the College}

The benefits for faculty completing a SPEED program are many and aid not only the individual, but the College as well. Benefits include the following:

- Faculty will be more competitive for educational-related grants (such as through NSF)

- Faculty will be more effective and efficient in and outside the classroom, leaving additional time for other technical pursuits

- Better education for students taught by formally qualified and certified educators will result in higher retention rates, better trained students and more-satisfied employers

- Faculty will better appreciate/respect educational aspects of colleagues work and certification will lead to nationwide recognition of professional engineering educators and positively impact the engineering society

\section{SPEED in Practice}

While some colleges are well-positioned to set up a SPEED program (they have a Center for Teaching \& Learning, have in-house faculty involved in engineering education, have a College of Education, have the requisite culture in the school, etc.), many will not. This creates a potential barrier for both buy-in and implementation. There are several ways to address this, some of which would need to be developed in support of this program. These include:

- Utilizing sectional meetings of ASEE as lower-cost opportunities to share scholarship and attend workshops

- Utilizing asynchronous on-line offerings (self-study modules, webinars) associated with some aspect of a SPEED program

- Utilizing corporate centers of excellence in professional faculty development to provide synchronous distance learning programs

\section{Concluding Remarks}

This proposal provides a relatively low-cost, high-impact approach to affecting a much needed and long discussed culture change within the higher education engineering community. Additionally, making a program such as SPEED compulsory (through linking with accreditation) can provide the necessary driving force to ensure that engineering education in the United States retains its respect as the best in the world. We are at a tipping point: we must provide the engineers of 2020 the appropriate education experience required to lead this Nation through the $21^{\text {st }}$ century.

\section{References}

[1] Grinter, L. E. (chairman), "Report of the ASEE Committee on Evaluation of Engineering Education,” J. Engr Educ., Sept. 25, 1955

[2] Schaefer, D. (2007): “Advising The Advisor: Professional Development of Junior Faculty”, In: Thomas, B. (Ed.), Proceedings of the ASEE Southeastern Section Annual Conference: "Advancing Scholarship in Engineering Education: Lessons Learned From a Year of Dialogue", Louisville, Kentucky, USA, April 1-3, 2007, pp. 2.12

[3] Schaefer, D. and T.T. Utschig (2008): "A Review of Professional Qualifications, Development, and Recognition of Faculty Teaching in Higher Education around the World", In: Proceedings of the 2008 ASEE Annual Conference \& Exposition, Pittsburgh, Pennsylvania, June 22-25, 2008 .

[4] Utschig, T.T. and D. Schaefer (2008): “Critical Elements for Future Programs Seeking to Establish Excellence in Engineering Education through Professional Qualification of Faculty Teaching in Higher Education", In: Proceedings of the IACEE 11th World Conference on Continuing Engineering Education, Atlanta, Georgia, May 20-23, 2008.

[5] Utschig, T.T. and D. Schaefer (2008): "Opportunities and Challenges in Professional Education-related Faculty Development in the US", In: Proceedings of the $38^{\text {th }}$ Annual Frontiers in Education Conference (FIE 2008), Saratoga Springs, New York, October $22-25,2008$. 